\title{
Selective Response of Human Airway Epithelia to Luminal but Not Serosal Solution Hypertonicity \\ Possible Role for Proximal Airway Epithelia as an Osmolality Transducer
}

Niels J. Willumsen, ${ }^{\star}$ C. William Davis, ${ }^{\star \star}$ and Richard C. Boucher*

*Departments of Medicine and ${ }^{\ddagger}$ Physiology, University of North Carolina, Chapel Hill, North Carolina 27599

\begin{abstract}
The response of cultured human nasal epithelia to hypertonic bathing solutions was tested using ion-selective microelectrode and quantitative microscopy. Raised luminal, but not serosal, osmolality $\left( \pm 150 \mathrm{mM}\right.$ mannitol) decreased $\mathrm{Na}^{+}$ absorption but did not induce $\mathrm{Cl}^{-}$secretion. Raised luminal osmolality increased cell $\mathrm{Cl}^{-}$activity, $\mathrm{Na}^{+}$activity, and transepithelial resistance and decreased both apical and basolateral membrane potentials and the fractional resistance of the apical membrane; equivalent circuit analysis revealed increases in apical, basolateral, and shunt resistances. Prolonged exposure $(10 \mathrm{~min})$ to $430 \mathrm{mos} M$ luminal solution elicited no regulation of any parameter. Optical measurements revealed a reduction in the thickness of preparations only in response to luminal hypertonic solutions. We conclude that (a) airway epithelial cells exhibit asymmetric water transport properties, with the apical membrane water permeability exceeding that of the basolateral membrane; (b) the cellular response to volume loss is a deactivation of the basolateral membrane $\mathrm{K}^{+}$conductance and the apical membrane $\mathrm{Cl}^{-}$conductance; (c) luminal hypertonicity slows the rate of $\mathrm{Na}^{+}$absorption but does not induce $\mathrm{Cl}^{-}$secretion; and $(d)$ cell volume loss increases the resistance of the paracellular path. We speculate that these properties configure human nasal epithelium to behave as an osmotic sensor, transducing information about luminal solutions to the airway wall. (J. Clin. Invest. 1994. 94:779-787.) Key words: lung • epithèlium • physiology • biological transport • waterelectrolyte balance
\end{abstract}

\section{Introduction}

Pulmonary airway surfaces are covered by a thin $(5-25 \mu \mathrm{m})$ film of liquid that is thought to be important for lung defense $(1,2)$. A number of recent studies have indicated that the volume and composition of this liquid layer is regulated by the superficial epithelium that lines the conducting airways (3-5). Although a comprehensive description of the metabolism of sur-

\footnotetext{
Address correspondence to Richard C. Boucher, M.D., Division of Pulmonary Diseases, Department of Medicine, 724 Burnett-Womack Building $229 \mathrm{H}$, University of North Carolina, Chapel Hill, NC 27514. Niels J. Willumsen's present address is Zoophysiological Laboratory, August Krogh Institute, University of Copenhagen, 13 Universitetsparken, DK2100 Copenhagen, Denmark.

Received for publication 30 April 1993 and in revised form 18 October 1993.
}

J. Clin. Invest.

(c) The American Society for Clinical Investigation, Inc.

0021-9738/94/08/0779/09 \$2.00

Volume 94, August 1994, 779-787 face liquids encompassing all regions of the lung has not been developed, studies of proximal airway epithelia indicate that absorption of salt by active and perhaps passive mechanisms constitutes the major basal ion flow (5). The requirement for absorption probably arises from the volume load imposed upon this region by the axial movement of liquids transported by the mucociliary clearance system from distal lung regions of large aggregate surface area to proximal airway surfaces of much smaller surface area.

There are likely conditions under which water evaporates from proximal airway surfaces into poorly conditioned inspired air $(6,7)$. Evaporative water loss in excess of replenishment in the proximal airways cools airway surfaces and raises the osmolality of airway surface liquids $(8,9)$. Recent attention has focused on these effects in man because of observations that exercise-induced asthma appears to be triggered by the inspiration of cool, dry air (8). Current evidence differs with regard to whether cooling or osmolality is the trigger for bronchoconstriction (10). Consequently, because of increasing interest in the role of the epithelium in controlling bronchomotor tone and particularly because of the potential importance of the interaction between hypertonic solutions and airway epithelial function, we have investigated the effects of raising the osmolality of the solutions bathing airway epithelia in vitro. To facilitate the analysis of the effects of increased osmolality alone, initial studies were performed using the noncharged molecule mannitol as the added solute. To test whether the effects noted with mannitol were pertinent to in vivo conditions, subsequent experiments were performed in which $\mathrm{NaCl}$ was the solute used to raise osmolality. Because of increased availability of tissues and because the function of primary cultures closely mimics that of the intact tissue (11-14), we elected to perform these studies with primary cultures derived from human nasal epithelium.

\section{Methods}

Tissue specimens. Nasal specimens were obtained from 17 subjects, mean age $37 \pm 8$ y; 10 males, 7 females. These specimens were typically removed under general anesthesia, for sleep apnea syndromes and nasal reconstruction. The use of these tissues for research was approved by the University of North Carolina Committee for the Protection of the Rights of Human Subjects.

Tissue culture. Culture procedures have been described in detail elsewhere (15). In brief, cells were detached from freshly resected specimens by incubation at $4^{\circ} \mathrm{C}$ in modified Eagle's medium (MEM) containing 0.1\% Protease 14 (Sigma Chemical Co., St. Louis, MO) and $100 \mu \mathrm{g} / \mathrm{ml}$ DNAase (Sigma Chemical Co.). Cells were isolated after $24-48 \mathrm{~h}$ by centrifugation $(800 \mathrm{~g})$, protease neutralized (10\% FBS), after which the cells were washed twice in MEM and suspended in a base medium (Ham's F-12) that contained seven hormones and growth factors as described previously (15). Cells $\left(3 \times 10^{5}\right.$ in $25 \mu \mathrm{l}$ media) were plated onto substrata affixed to polycarbonate cups housed in sixwell containers (Costar, Cambridge, MA) containing media in both the 
basal and apical compartments. For microelectrode studies, the substratum was a polymerized collagen sheet; for optical studies, it was a Falcon Cyclopore membrane (Becton Dickinson, Lincoln Park, NJ). After $16 \mathrm{~h}$ in the tissue culture incubator (Queue Systems, Inc., Parkersburg, WV) exposed to $5 \% \mathrm{CO}_{2}$ air at $37^{\circ} \mathrm{C}$, the nonadherent cells were removed by washing. The cells were fed daily for $5 \mathrm{~d}$ with F-12 supplemented with seven hormones/growth factor media (F12-7X), after which they were fed with F12-7X supplemented (1:1) with 3T3 cell conditioned media (MEM) containing 2\% FBS. The cells were monitored daily by phase contrast microscopy (Nikon, Tokyo, Japan) and by measurement of the transepithelial potential difference $\left(V_{1}\right)$ using calomel electrodes interfaced to an electrometer (WPI EVO-M, Sarasota, FL). Cell preparations were routinely studied within $1-2 \mathrm{~d}$ of the development of the maximal $V_{\mathrm{t}}{ }^{1}$

Solutions and drugs. D-mannitol (Sigma Chemical Co.) and $\left[{ }^{14} \mathrm{C}\right]-$ mannitol (New England Nuclear, Boston, MA) were used. Amiloride was a gift from Merck, Sharpe, and Dohme (West Point, PA). For microelectrode studies, a standard KBR was used (12); for optical studies a TES-buffered Ringer (TBR) was used (16).

Transepithelial and intracellular measurements. For microelectrode studies, tissue culture cups were placed in a modified Ussing chamber that permitted perfusion (peristaltic pump model 97; LKB Instruments Inc., Bromma, Sweden) of the luminal and serosal sides of the culture with gassed $\left(95 \% \mathrm{O}_{2}-5 \% \mathrm{CO}_{2}\right)$ and warmed $\left(37^{\circ} \mathrm{C}\right) \mathrm{KBR}$ solution $(\mathrm{pH}$ $=7$ ). Remote-controlled magnetic valves were used to switch solutions in the luminal and serosal compartments. The volume of the luminal and serosal bathing solutions was $0.6 \mathrm{ml}$ and the flow rate was $5 \mathrm{ml} /$ min. Direct measurements of the rate changes in solution composition in each compartment showed that a complete solution change was effected within 30-60 s. The transepithelial potential $\left(V_{t}\right)$ across the cell layer was measured via $3 \mathrm{M} \mathrm{KCl}$-agar bridges positioned within $2 \mathrm{~mm}$ of the epithelial surface, which were connected by calomel electrodes (Radiometer, Copenhagen, Denmark) to a high impedance voltmeter (WPI FD223). The luminal bath served as common ground for both the macroelectrode and microelectrode systems. Transepithelial current pulses were passed across the epithelial sheet via $3 \mathrm{M} \mathrm{KCl}$-agar bridges connected by a pair of $\mathrm{Ag} / \mathrm{AgCl}$ electrodes to a stimulus isolation unit (model $305 \mathrm{WPI}$ ). The isolation unit was connected to a stimulus generator (Anapulse Stimulator, WPI) configured to pass $0.5 \mathrm{~s}$ current $(I)$ pulses $(1-10 \mu \mathrm{amp})$ every $6 \mathrm{~s}$. The total transepithelial resistance $\left(R_{\mathrm{t}}\right)$ was calculated from the current induced reflections in $V_{\mathrm{t}}$ as $R_{\mathrm{t}}=\Delta V_{\mathrm{t}} /$ $I$. Equivalent short circuit current $\left(I_{\mathrm{eq}}\right)$ was calculated as $I_{\mathrm{eq}}=V_{\mathrm{t}} / R_{\mathrm{t}}$. Because the transepithelial current voltage relationships are linear and time independent in the physiologic range of potentials, the $I_{\mathrm{eq}}$ accurately estimates the true short circuit current.

Microelectrodes. The intracellular $\mathrm{Na}^{+}\left(a_{\mathrm{c}}{ }^{\mathrm{Na}}\right)$ and $\mathrm{Cl}^{-}$activities $\left(a_{\mathrm{c}}^{\mathrm{Cl}}\right)$ were measured with double-barreled ion-selective microelectrodes. As previously described $(12,13)$, these electrodes were constructed from borosilicate glass capillaries (reference barrel, $1.2 \mathrm{~mm}$ outer diameter; ion-selective barrel, $1.5 \mathrm{~mm}$ outer diameter) that were glued together with epoxy (Araldit, Copenhagen, Denmark) and pulled on a horizontal puller (PD-5; Narishige, Tokyo, Japan). The ion-selective barrel was exposed to dichlorodimethylsilane vapor for $8-15 \mathrm{~s}$ and heated for $1 \mathrm{~h}$ at $100^{\circ} \mathrm{C}$. The tip of the ion-selective barrel was backfilled with either a neutral $\mathrm{Na}^{+}$ionophore $\left(\mathrm{Na}^{+}\right.$cocktail A [71176] Fluka AG, Buchs, Switzerland] or $\mathrm{Cl}^{-}$ion exchanger (477913; Corning, Medfield, MA) and the reference barrel was backfilled with $0.5 \mathrm{M} \mathrm{Na}_{2} \mathrm{SO}_{4}$ or $3 \mathrm{M} \mathrm{KCl}$.

1. Abbreviations used in this paper: $a_{\mathrm{c}}{ }^{\mathrm{Na}}$, intracellular $\mathrm{Na}^{+}$activity; $a_{\mathrm{c}}^{\mathrm{Cl}}$, intracellular $\mathrm{Cl}^{-}$activity; $E_{\mathrm{m}}$, membrane electromotive force; $f R_{\mathrm{a}}$, fractional resistance of the apical membrane; $I$, applied transepithelial constant current; $I_{\text {eq }}$, equivalent short-circuit current; KBR, Krebs bicarbonate Ringer; $P_{\mathrm{a}}^{\mathrm{Cl}}$, apical membrane $\mathrm{Cl}^{-}$permeability; $P_{\mathrm{a}}^{\mathrm{Na}}$, apical membrane $\mathrm{Na}^{+}$permeability; $R_{\mathrm{a}}$, apical membrane resistance; $R_{\mathrm{b}}$, basolateral membrane resistance; $R_{\mathrm{s}}$, shunt pathway resistance; $R_{\mathrm{t}}$, transepithelial resistance; TBR, TES-buffered Ringer; $V_{\mathrm{a}}$, apical membrane potential difference; $V_{\mathrm{t}}$, transepithelial potential difference; $V_{\mathrm{x}}$, ion-selective microelectrode voltage signal.
The sensitivity of the electrodes was determined before and after each experiment by recording the voltage shift measured by the ion-selective barrel in response to a 10 -fold change in ion concentration in constant ionic strength calibration solutions. The average sensitivity for $\mathrm{Cl}^{-}$selective electrodes was $-51 \pm 2 \mathrm{mV} /$ decade increase in $\mathrm{Cl}^{-}$activity at $23^{\circ} \mathrm{C}$, and the sensitivity for the $\mathrm{Na}^{+}$electrodes was $56 \mathrm{mV} / \mathrm{decade}$ increase in $\mathrm{Na}^{+}$activity $\left(23^{\circ} \mathrm{C}\right)$. The average resistance of the reference barrels was $90 \pm 10 \mathrm{MOhm}(n=55)$. The response time (90\% of full response) for the $\mathrm{Cl}^{-}$selective electrodes was $<2 \mathrm{~s}$ whereas the response for the $\mathrm{Na}^{+}$selective electrodes was $<10 \mathrm{~s}$. Other characteristics and the selectivity coefficients for these electrodes have been published previously $(12,13)$.

Intracellular measurements. The barrels of the microelectrode were connected to high impedance electrometers for measurement of the reference (WPI N-707A) and ion-selective signals (WPI FD233), respectively. The apical membrane potential $\left(V_{\mathrm{a}}\right)$, the ion-selective electrode signal $\left(V_{\mathrm{x}}\right)$, and $V_{\mathrm{t}}$ were recorded on a four-channel recorder (model 7045; Linseis, Inc., Princeton Junction, NJ). All impalements were performed perpendicular to the surface of the cell cultures with a remotecontrolled hydraulic micromanipulator (MO-103; Narishige).

The fractional resistance of the apical membrane $\left(f R_{\mathrm{a}}\right)$ was calculated by the equation

$f R_{\mathrm{a}}=\Delta V_{\mathrm{a}} / \Delta V_{\mathrm{t}}=R_{\mathrm{a}} /\left(R_{\mathrm{a}}+R_{\mathrm{b}}\right)$,

where $R_{\mathrm{a}}$ and $R_{\mathrm{b}}$ are the resistances of the apical and basolateral membranes, respectively.

Intracellular ion activities were calculated as follows:

$a_{\mathrm{c}}{ }^{\mathrm{x}}=a_{0}{ }^{\mathrm{x}} \times 10^{\left[\Delta\left(\mathrm{v}_{\mathrm{x}}-\mathrm{v}_{\mathrm{ref}}\right) / \mathrm{s}\right]}$,

where $a_{0}{ }^{\mathrm{x}}$ is the activity of the ion (x) in $\mathrm{KBR}\left(\mathrm{Na}^{+} 104 \mathrm{mM} ; \mathrm{Cl}^{-} 89\right.$ $\mathrm{mM}$ ), assuming activity coefficients of $0.75 ; V_{\text {ref }}$ is the signal from the reference electrode; $\Delta\left(V_{\mathrm{x}}-V_{\text {ref }}\right)$ the change in $V_{\mathrm{x}}-V_{\text {ref }}$ upon impalement, and $S$ is the sensitivity as defined above.

The criteria for successful impalements were similar to those previously described $(12,13)$ : $(a)$ an instantaneous deflection in the potential sensed by the reference electrode coupled with the appearance of deflections in the signals in response to transepithelial current pulses; (b) the potential recorded by the ion-selective barrel should be stable within 2 or $10 \mathrm{~s}$ for $\mathrm{Cl}^{-}$and $\mathrm{Na}^{+}$electrodes, respectively; (c) both the reference and the ion-selective signals should return to within $2 \mathrm{mV}$ of their preimpalement values upon withdrawal of the electrode from the cell; and $(d)$ the measured potential should be stable for a minimum of $30 \mathrm{~s}$.

Sign conventions. The apical membrane potential was referenced to the luminal bath potential as follows: $V_{\mathrm{a}}=\psi_{\mathrm{c}}-\psi_{1}$ (where $\psi_{\mathrm{c}}$ and $\psi_{1}$ are the electric potentials of the intracellular and luminal compartments, respectively). Transepithelial potential and basolateral membrane potentials are referenced to the serosal bath: $V_{\mathrm{t}}=\psi_{1}-\psi_{\mathrm{s}}$ and $V_{\mathrm{b}}=\psi_{\mathrm{c}}-\psi_{\mathrm{s}}$ (where, $\psi_{\mathrm{s}}$ is the electric potential of the serosal compartment).

Model calculations. The apical and basolateral permeabilities for the transported ions, the individual resistances to ion flow at each barrier, and the resistance of the shunt pathway $\left(R_{\mathrm{s}}\right)$ were calculated using an equivalent circuit analysis (11) based on measurements of the transepithelial and intracellular electrophysiologic parameters and of intracellular ion activities.

Protocols. In the initial series of microelectrode studies, mannitol was applied incrementally to the luminal or serosal compartment in 50 mosM steps every $5 \mathrm{~min}$. Subsequent experiments measured the effects of raising luminal solution osmolality to $430 \operatorname{mos} M(+150$ mosM mannitol) for $10 \mathrm{~min}$ to measure the time course of the response to this maneuver. For this protocol, both $\mathrm{Na}^{+}$- and $\mathrm{Cl}^{-}$-selective microelectrodes were used. Prolonged $(10 \mathrm{~min})$ perfusion of the basolateral membrane with 150 mosM mannitol added to KBR was also performed. To allow calculations of individual membrane permeabilities under control and hyperosmolal conditions, the cultures were exposed to the following sequence: KBR; amiloride; KBR; hypertonic solution (KBR plus 150 mosM mannitol for $10 \mathrm{~min}$ ); and finally hypertonic solutions containing amiloride $\left(10^{-4} \mathrm{M}\right)$. This protocol was performed using both $\mathrm{Na}^{+}$- and 
$\mathrm{Cl}^{-}$-sensitive microelectrodes. In a final series of experiments, the effects of 150 mosM added $\mathrm{NaCl}$ to the luminal and serosal baths over a 10-min interval was measured with $\mathrm{Cl}^{-}$-selective microelectrodes.

$\left[{ }^{14} \mathrm{C}\right]$ Mannitol permeability measurements. Radiolabeled mannitol has been used previously to measure the permeability of the paracellular path in airway epithelia (17). For these measurements, tissue culture cups were placed in modified Ussing flux chambers as described in detail previously (12). $\left[{ }^{14} \mathrm{C}\right]$ Mannitol $(10 \mu \mathrm{Ci} /$ chamber) were added to either the luminal or basolateral compartments $(6 \mathrm{ml})$. The sink and source solutions were sampled ( 1 and $0.05 \mathrm{ml}$, respectively) every 10 min for four intervals, after which the luminal solution osmolality was raised to 430 mosM by the addition of 150 mosM of unlabeled mannitol. $\left[{ }^{14} \mathrm{C}\right]$ Mannitol permeation was measured for an additional four 10-min intervals. After addition of scintillant the samples were counted for ${ }^{14} \mathrm{C}$ radioactivity in a liquid scintillation spectrometer and mannitol permeabilities were calculated as previously described (17).

Epithelial thickness measurements. Because the plasma membrane of living cultured cells is difficult to visualize, even by Nomarski optics, it was impossible to determine cell volume from a reconstruction of cells from optical sections of the cultures $(16,18)$. Thus, the effects of increased osmolality on cell volume were instead estimated by measuring the thickness of the epithelium over time (19), using physical markers of the luminal and basal barriers of the culture. The $0.4-\mu \mathrm{m}$ pores in the Cyclopore substratum served to mark the basal plane of the cultures. The luminal surface was labeled by the spontaneous attachment of $1-\mu \mathrm{m}$ microbeads during a 30-40-min incubation of cultures with a suspension of Fluoresbrite latex beads (Polysciences, Inc., Warrington, PA). The labeled cultures were mounted in an Ussing chamber modified for microscopy (20) and perfused continuously on both sides by a perfusion system that delivered a new solution to the tissue in 20-40 s. The stage of the microscope and the perfusion system were housed in a temperature-controlled box maintained at $36-37^{\circ} \mathrm{C}$. The tissues were viewed with a Zeiss IM microscope equipped with differential interference contrast (Nomarski) and epifluorescence optics, using a Zeiss Neofluar 100/1.3 N.A. objective and a 1.4 N.A. condenser. To avoid the problems associated with precisely locating objects in the $z$-axis in fluorescence microscopy (21), the luminal beads were imaged with DIC optics; fluorescence microscopy was used only to locate and identify luminal beads. A stepper motor mounted on the coarse focus of the microscope was used to focus the microscope through the tissue in 1.0$\mu \mathrm{m}$ steps at $15 \mathrm{steps} / \mathrm{s}$, under computer control and in synchrony with the video system. The optical image was monitored with a video camera (Dage 72 CCD; Dage-MTI Inc., Michigan City, IN) whose output was modified by an image processing system to contain identifying, alphanumeric information. During a $z$-axis scan, the distance from the starting point at the apical membrane was written in real-time by the computer into the video signal and the signal was recorded on S-VHS video tape (BV-1000; Mitsubishi). After an experiment, video records were analyzed on a frame-by-frame basis, and epithelial thickness was determined for each $z$-axis scan by reading the focal plane displacement from the video record at the point where a pore marking the substratum first came into sharp focus. The time course of the experiment was unknown to the person analyzing the videotape records to ensure an unbiased data set.

To check that the Cyclopore substratum has a water permeability greater than that likely for the basolateral membrane of the epithelial cells, the osmotic permeabilities of two filters were determined. Transfilter water flows under a $30-\mathrm{cm}$ hydrostatic pressure head yielded hydraulic conductivities of 0.043 and $0.047 \mathrm{~cm} \mathrm{~s}^{-1} \mathrm{~atm}^{-1}$. Expressed as equivalent osmotic permeabilities, the values of 57.6 and $64.0 \mathrm{~cm}$ $\mathrm{s}^{-1}$ are more than three orders of magnitude higher than the $P_{\text {osm }}$ of Necturus gallbladder apical and basolateral membranes (18). Because the gallbladder possesses the highest membrane osmotic permeabilities known for sheet epithelia and the filters are $>1,000$ times more permeable, it is highly likely that the rate-limiting step for water flow from the serosal compartment into the nasal epithelial cells is the basolateral membrane and not the substratum.

The protocol used for these experiments paralleled those used for bioelectric measurements. Baseline epithelial thickness was determined

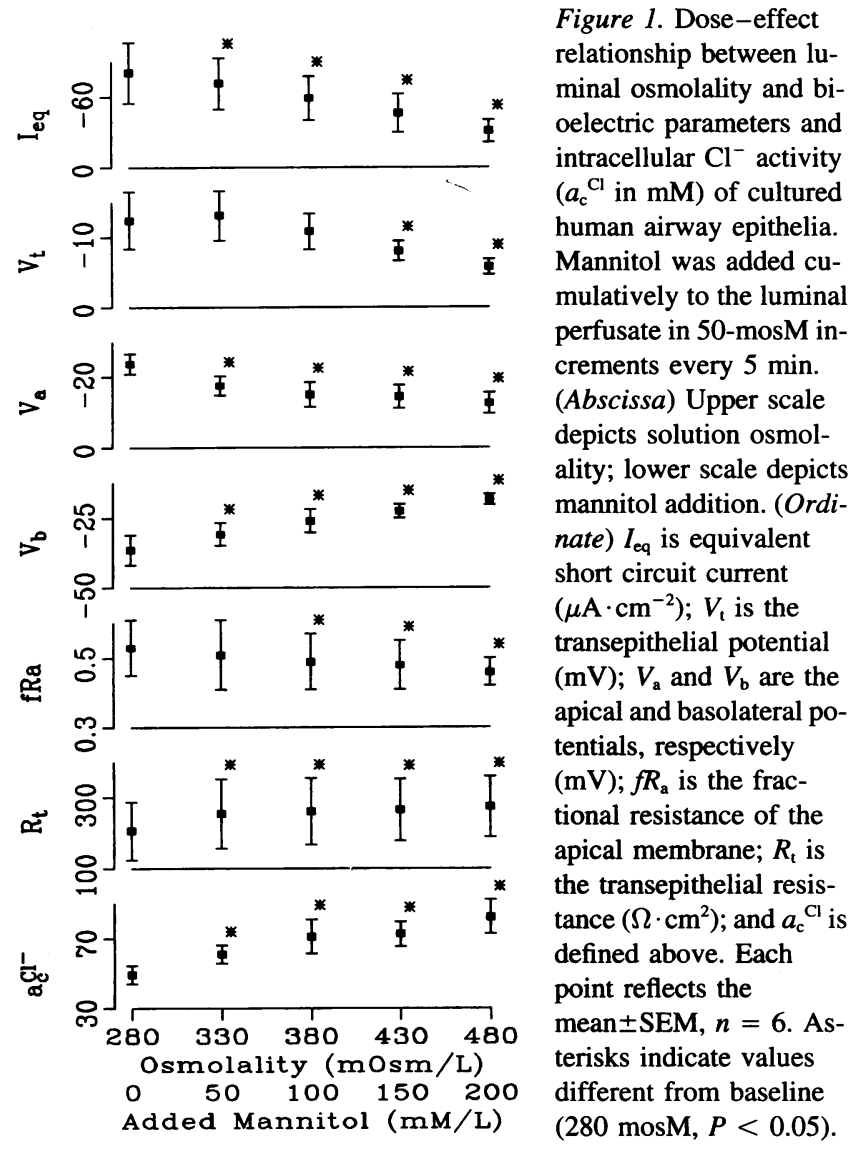

in cultures exposed to TBR on both sides. Further measurements were then made at 30- or 60-s intervals as luminal and/or serosal solution osmolality was increased by adding $150 \mathrm{mM}$ mannitol or returned to isotonic conditions by its removal.

Statistical analyses. Data are reported as the mean \pm SE. Differences between means were tested with a paired $t$ test, generally between the mean of all control points and each subsequent measurement. The paired differences reported between any other means are stated explicitly in Figures and Tables. Differences were considered significant at the $P$ $\leq 0.05$ level. Only one culture per donor was used in an experiment; thus, the number of observations $(n)$ represents the number of individuals.

\section{Results}

Dose effect relationships between luminal osmolality and cellular electrical responses. The effects of increasing concentrations of mannitol in the luminal bath on transepithelial and intracellular parameters of human nasal epithelial cultures are depicted in Fig. 1. Increasing luminal osmolality with mannitol incrementally every $5 \mathrm{~min}$ reduced $I_{\text {eq }}$ and $V_{\mathrm{t}}$, depolarized $V_{\mathrm{a}}$ and $V_{\mathrm{b}}$, decreased $f R_{\mathrm{a}}$, and increased $R_{\mathrm{t}}$ and $a_{\mathrm{c}}{ }^{\mathrm{Cl}}$ in a dosedependent manner.

Effect of raised luminal solution osmolality (150 mosM mannitol). The effects of luminal hypertonicity on airway epithelia over a prolonged time period were examined. The basal (KBR) transepithelial and intracellular parameters shown in Fig. $2 A$ are similar to those for normal human nasal epithelia reported previously $(12,15)$. Addition of 150 mosM mannitol to the KBR bathing the lumen induced small but significant reductions in $I_{\mathrm{eq}}$ and large increases in $R_{\mathrm{t}}$. Additionally, $V_{\mathrm{a}}$ and $V_{\mathrm{b}}$ rapidly 

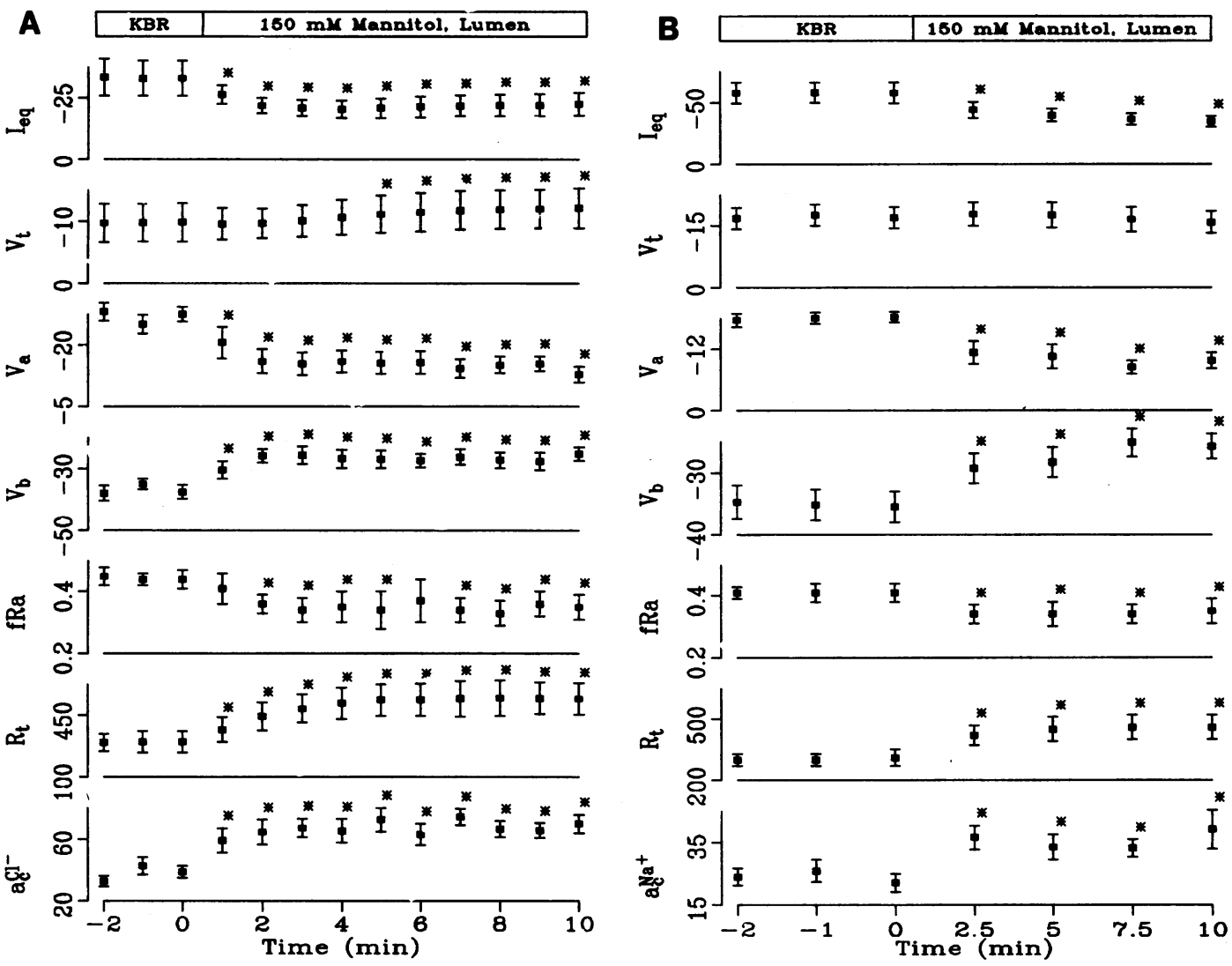

Figure 2. Effects of luminal hypertonic solutions on the bioelectric properties of cultured human airway epithelia. Mannitol (150 mM) was added to $\mathrm{KBR}$ at time 0 . Each point is the mean $\pm \operatorname{SEM}(n=8)$ and asterisks indicate values significantly different from $\mathrm{KBR}$ alone $(P<0.05)$. $(A)$ Experiments measuring $a_{\mathrm{c}}{ }^{\mathrm{Cl}}$. $(B)$ Experiments measuring $a_{\mathrm{c}}{ }^{\mathrm{Na}}$. Note the change in time scale after 0 time point. See Fig. 1 for units.

depolarized, with the change in $V_{\mathrm{a}}$ being somewhat smaller as indicated by the significant increase in $V_{\mathrm{t}} . f R_{\mathrm{a}}$ showed a significant decrease in response to mannitol addition. Intracellular $\mathrm{Cl}^{-}$ activity $\left(a_{\mathrm{c}}{ }^{\mathrm{Cl}}\right)$ increased by $\sim 60 \%$ in response to this maneuver. No evidence of compensation (i.e., cell volume regulation) in transepithelial or intracellular bioelectric or ion activity parameters was detected over the 10-min exposure to luminal hypertonicity. The effects of raised osmolality were rapidly reversible. Similar effects were noted when sucrose was used as the solute rather than mannitol (not shown).

Identical electrical responses were observed when measurements were made with $\mathrm{Na}^{+}$-selective electrodes (Fig. $2 \mathrm{~B}$ ). These experiments showed that intracellular $\mathrm{Na}^{+}$activity rose from 20.3 to $36 \mathrm{mM}$ during the course of mannitol superfusion. No backregulation of $a_{\mathrm{c}}^{\mathrm{Na}}$ towards control values was observed during mannitol administration.

Exposure of basolateral membrane to raised osmolality $(150$ mosM mannitol). In marked contrast to luminal challenges, no responses were seen in dose-effect relationships between serosal osmolality and culture bioelectric properties. Fig. 3 shows the data obtained from a 10-min exposure of the serosal surface to a solution of KBR plus 150 mosM mannitol. Despite the prolonged exposure, no transepithelial or cellular bioelectric effects were detected and no changes in $a_{\mathrm{c}}{ }^{\mathrm{Cl}}$ were noted.

Effect of raised luminal osmolality (150 mosM $\mathrm{NaCl})$. The effects of increasing luminal osmolality by $\sim 150$ mosM with added $\mathrm{NaCl}$ (Fig. 4) were qualitatively similar to the effects observed with added mannitol, but the effects on bioelectric parameters were generally lower in magnitude. Thus, as with raised mannitol, adding $75 \mathrm{mM} \mathrm{NaCl}$ luminally caused an increase in $R_{\mathrm{t}}$ and a decrease in $I_{\mathrm{eq}}$, a decrease in $f R_{\mathrm{a}}$, and depolarization of both $V_{\mathrm{a}}$ and $V_{\mathrm{b}}$. The maneuver also caused an increase in $a_{\mathrm{c}} \mathrm{Cl}^{-}$. During the 10-min exposure to increased luminal $\mathrm{NaCl}$, there was no tendency in any of the observed parameters to return toward their baseline values.

Increasing serosal osmolality by adding $75 \mathrm{mM} \mathrm{NaCl}$ to KBR had no effect on the bioelectric properties of the cultures nor were there any effects on $a_{\mathrm{c}}^{\mathrm{Cl}}$ (data not shown).

Effect of amiloride block of apical membrane $\mathrm{Na}^{+}$conductance during luminal hypertonicity. The effects of the $\mathrm{Na}^{+}$channel blocker amiloride on human nasal airway epithelia before and during exposure to 150 mosM of mannitol in the luminal solution are shown in Fig. 5. As previously reported, under control conditions, amiloride reduces $I_{\mathrm{eq}}$ and $V_{\mathrm{t}}$, hyperpolarizes $V_{\mathrm{a}}$, and induces small increases in $f R_{\mathrm{a}}$ and $R_{\mathrm{t}} \cdot a_{\mathrm{c}}^{\mathrm{Cl}}$ routinely does not change during amiloride exposure. The addition of 150 mosM mannitol-KBR to the lumen induced changes similar to those shown in Fig. 2. Addition of amiloride to cultures during luminal mannitol hypertonic exposure induced changes similar to those observed with amiloride alone with one exception: in cultures exposed to hypertonic solutions, amiloride significantly reduced $a_{\mathrm{c}}^{\mathrm{Cl}}$. Similar changes were observed when $\mathrm{NaCl}$ instead of mannitol was elevated in the luminal bath (Fig. 4).

In a second series of studies, the same sequence of amiloride before and after mannitol was administered to human airway epithelia and the intracellular response was recorded with intra- 


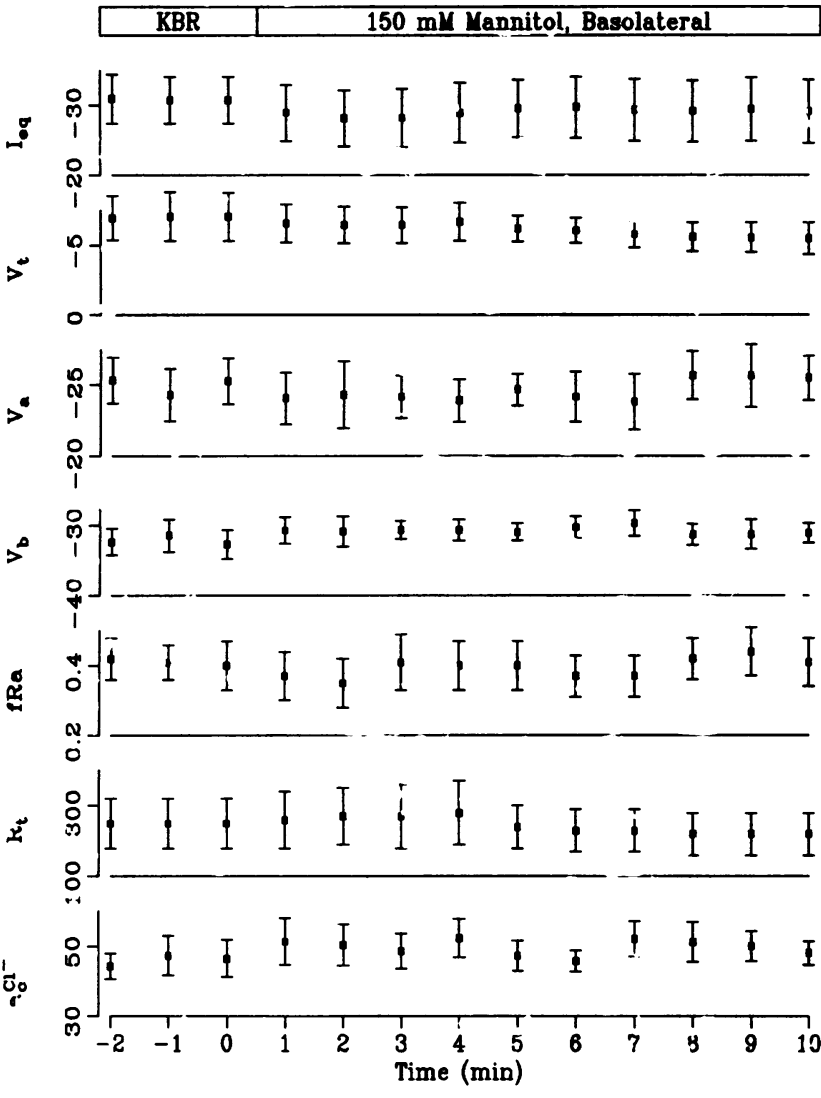

Figure 3. Effects of basolateral hypertonic solutions on the bioelectric properties and intracellular $\mathrm{Cl}^{-}$activity of cultured human airway epithelia. Mannitol $(150 \mathrm{mM})$ was added to KBR at time 0 . Each point reflects the mean $\pm \operatorname{SEM}(n=7)$. No significant changes were observed in any parameter over the 10-min exposure. See Fig. 1 for units.

cellular $\mathrm{Na}^{+}$-selective electrodes. As shown in Fig. 6, the response in transepithelial and intracellular bioelectric parameters to amiloride and mannitol were similar to those shown in Fig. 5. As previously reported (13), intracellular $\mathrm{Na}^{+}$activity does not decrease after amiloride exposure alone; Fig. 6 shows that amiloride also had no effect when $a_{\mathrm{c}}{ }^{\mathrm{Na}}$ was elevated by luminal hypertonicity. Because luminal mannitol hypertonicity alone reduced $I_{\mathrm{eq}}(\sim 14 \%)$, the magnitude of the reduction in $I_{\mathrm{eq}}$ caused by amiloride addition was less, relative to its effects observed under isotonic conditions. The smaller $I_{\text {eq }}$ in the presence of mannitol may therefore reflect a slower rate of $\mathrm{Na}^{+}$ absorption, which could reflect either a decrease in the apical membrane $\mathrm{Na}^{+}$permeability, a decrease in the electrochemical driving force for $\mathrm{Na}^{+}$entry, or inhibition of $\mathrm{Na}^{+}-\mathrm{K}^{+}$ATPase activity. Because $a_{\mathrm{c}}{ }^{\mathrm{Na}}$ rises and $V_{\mathrm{a}}$ depolarizes in response to luminal hypertonicity, the electrochemical driving force for $\mathrm{Na}^{+}$ absorption decreases. Amiloride does not lower intracellular $\mathrm{Na}^{+}$during luminal mannitol hypertonicity, in contrast to its effects on $a_{\mathrm{c}}{ }^{\mathrm{Cl}}$ under the same conditions.

Model calculations with luminal mannitol hypertonicity. The effects of luminal mannitol hypertonicity on the ion permeabilities, membrane and shunt resistances, and transmembrane electromotive forces $\left(E_{\mathrm{m}}\right)$ of the epithelial cultures were calculated as previously described (11). The assumptions for these calculations are that $\mathrm{Na}^{+}$and $\mathrm{Cl}^{-}$are the two major ions carrying charge across the apical membrane and that amiloride effectively reduces the $\mathrm{Na}^{+}$conductance to zero. Bioelectric parame-

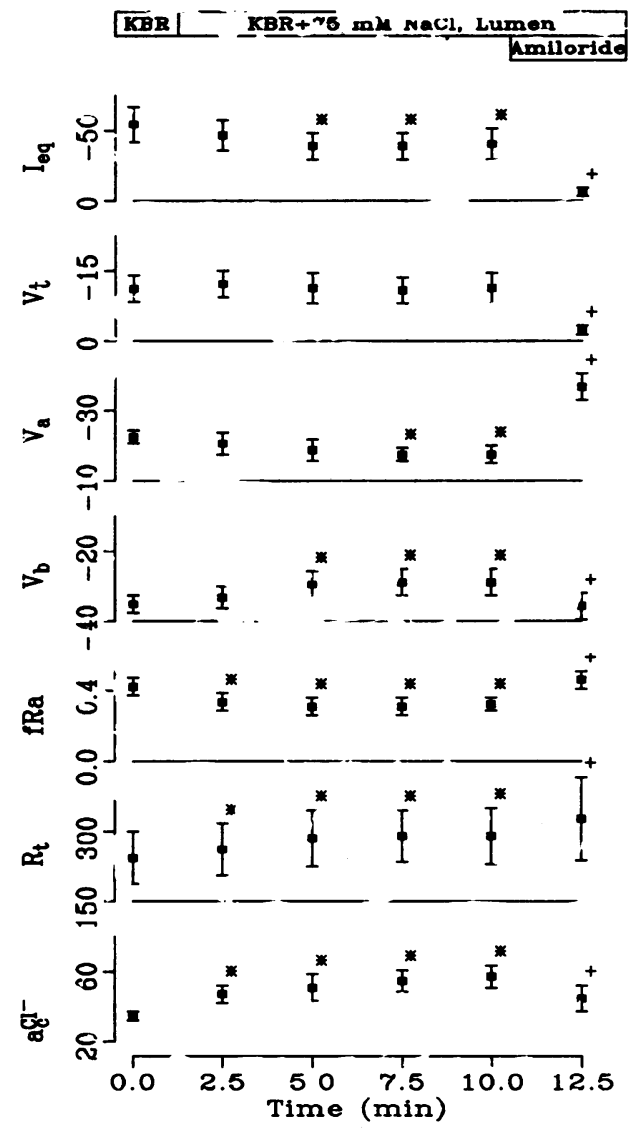

Figure 4. Effects of $\mathrm{NaCl}$ as the osmotic agent in a luminal hypertonic challenge $(+150$ mosM). At time 0 , an additional $75 \mathrm{mM} \mathrm{NaCl}$ was added to KBR. Each point is the mean $\pm \operatorname{SEM}(n=6)$ and asterisks indicate values significantly different from KBR alone $(P<0.05)$; + indicates significant $(P<0.05)$ changes from 10 -min time point with added $\mathrm{NaCl}$. See Fig. 1 for units.

ters from the experiment shown in Figs. 5 and 6 were summarized (Table I) and the derived parameters are shown in Table II. The parameters determined for baseline conditions and amiloride exposure are similar to those previously reported (11). Multiple effects on these parameters were induced by hypertonic luminal solutions. The resistances of all epithelial elements increased: $R_{\mathrm{a}}$ increased $\sim 12 \%$ and $R_{\mathrm{b}}$ increased $21 \%$. An increase of $\sim 75 \%$ in $R_{\mathrm{s}}$ was calculated. The increase in $R_{b}$ exceeded that of $R_{\mathrm{a}}$. The EMFs of both membranes became more positive with the change in $E_{\mathrm{b}}$ slightly exceeding that in $E_{\mathrm{a}}$. A large reduction in the driving force for $\mathrm{Na}^{+}$entry and a small increase in the driving force favoring $\mathrm{Cl}^{-}$secretion were detected. Finally, apical membrane $\mathrm{Cl}^{-}$permeability $\left(P_{\mathrm{a}}^{\mathrm{Cl}}\right)$ was decreased by $42 \%$, whereas $P_{\mathrm{a}}^{\mathrm{Na}}$ decreased by only $10 \%$.

Measurements of $\left[{ }^{14} \mathrm{C}\right]$ mannitol permeability. Although the anatomic correlate of $R_{\mathrm{s}}$ has not been rigorously assigned in this preparation, it likely reflects the resistance of the paracellular path. Consequently, the increase in $R_{\mathrm{s}}$ noted with raised luminal osmolality suggests that the resistance of the paracellular path is increased. This hypothesis was tested independently by measuring the permeability of the cultures to $\left[{ }^{14} \mathrm{C}\right]$ mannitol before and during raised luminal osmolality. In the baseline condition, $\left[{ }^{14} \mathrm{C}\right]$ mannitol permeabilities were $1.03 \pm 0.18 \times 10^{-7}$ $\mathrm{cm} \cdot \mathrm{s}^{-1}$. No differences were seen between the mucosal to serosal versus serosal to mucosal ion flows. In response to raised 


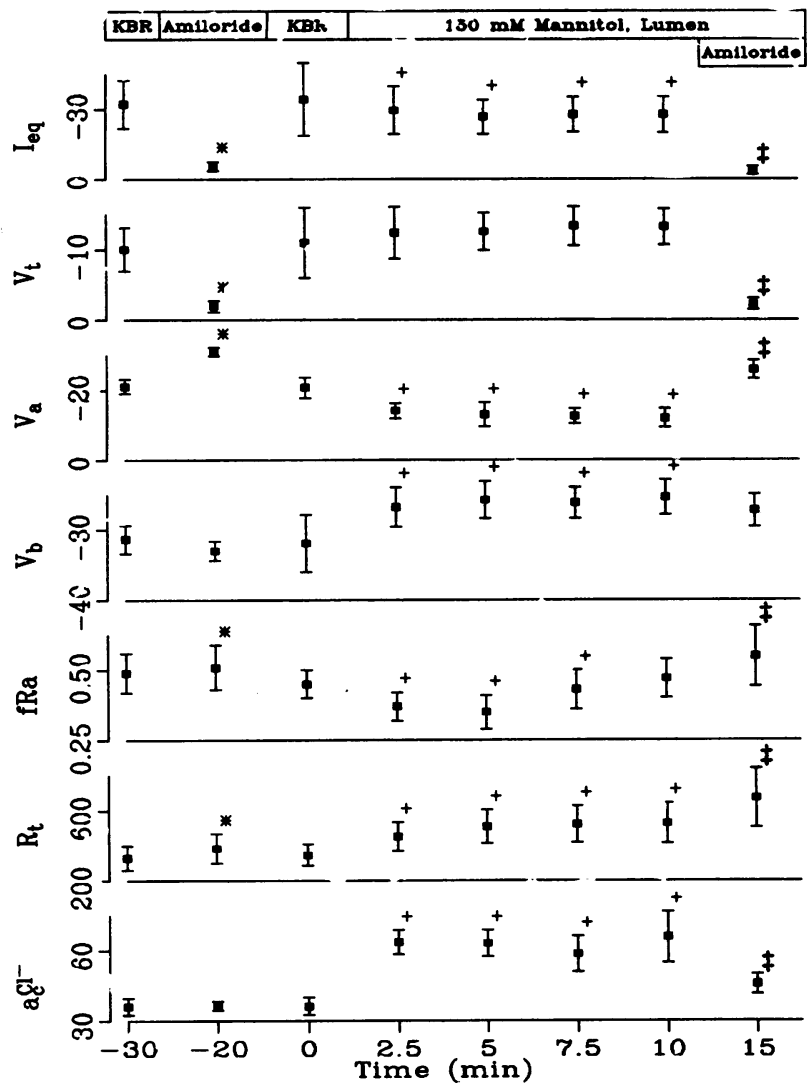

Figure 5. Effects of sequential exposure of human airway epithelia to amiloride $\left(10^{-4} \mathrm{M}\right)$, luminal hypertoxicity, and luminal hypertonicity plus amiloride $\left(10^{-4} \mathrm{M}\right)$ on bioelectric parameters and $a_{\mathrm{c}}^{\mathrm{Cl}}$. Asterisks depict significant $(P<0.05)$ changes induced by amiloride from baseline $(K B R) ;+$ depicts significant $(P<0.05)$ change from KBR induced by luminal hypertonicity; $\ddagger$ depicts significant change from 10 -min time point with $150 \mathrm{~mm}$ mannitol. Each point reflects mean $\pm S E M, n=7$. Note changes in time scale. See Fig. 1 for units.

luminal osmolality, the mannitol permeability decreased to value of $0.54 \pm 0.21 \times 10^{-7} \mathrm{~cm} \cdot \mathrm{s}^{-1}(P<0.05 ; n=6)$. Proportionate reductions in mannitol permeability were detected regardless of flux direction.

Cell volume. The effects of luminal hypertonicity (TBR $+150 \mathrm{mM}$ mannitol) on epithelial thickness were rapid and reversible (Fig. 7): the thickness of the cultures decreased by $32 \pm 5.2 \%$ to a new steady state in $\leq 1 \mathrm{~min}$ from a mean starting thickness of $29.3 \pm 4.3 \mu \mathrm{m}$ (Table III). The predicted change for a ideal osmometer, which changes volume solely through a change in height, is $-34.9 \%$. Because this value is not different from the observed change in epithelial thickness, the cells in the epithelial cultures probably do not collapse laterally, but shrink solely through a loss of cell height. After the initial shrinkage, epithelial thickness was stable throughout the 15min luminal hypertonic exposure, and it then rapidly returned to the original thickness upon return to isotonic TBR.

In contrast to luminal hypertonicity, increasing serosal solution osmolality had no effect on epithelial thickness (Fig. 7): after $5 \mathrm{~min}$ of serosal hypertonicity, the thickness of the epithelium changed $<1 \%$ from its control value (Table III). When, during serosal hypertonic exposure, luminal osmolality was again elevated, the epithelium again decreased in thickness,
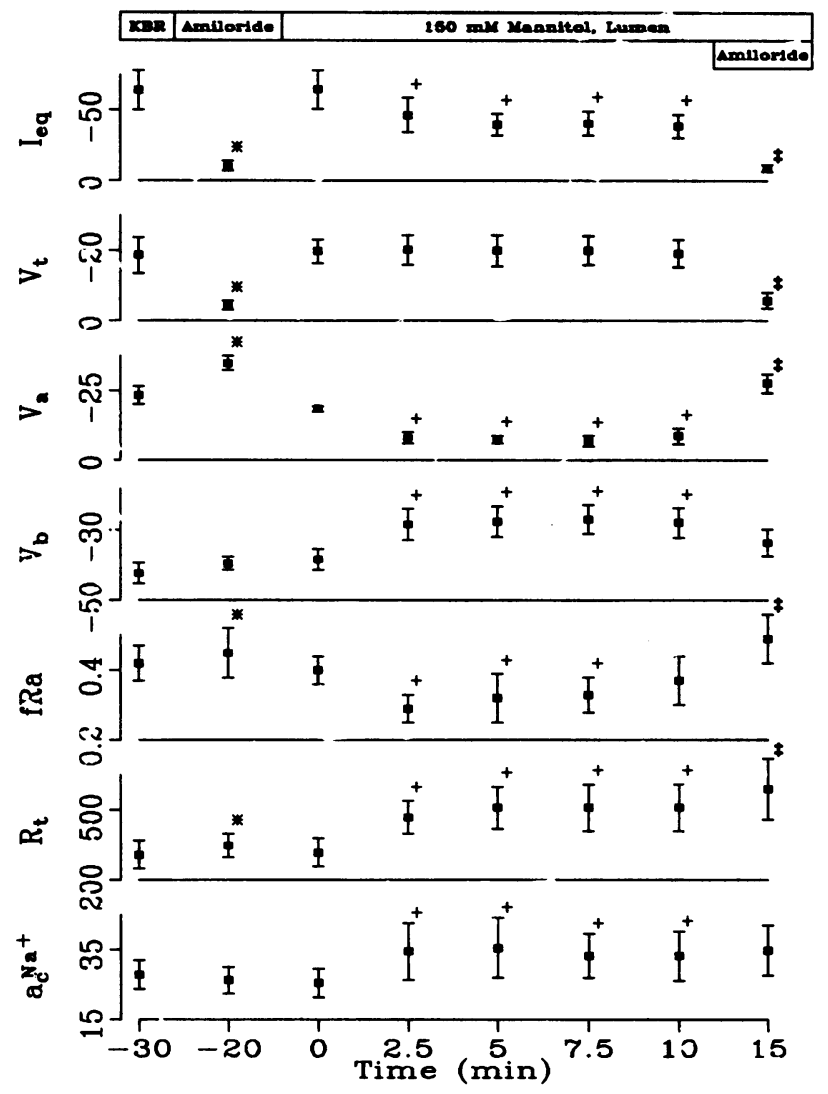

Figure 6. Effects of sequential exposure of human airway epithelia to amiloride $\left(10^{-4} \mathrm{M}\right)$, luminal hypertoxicity, and luminal hypertonicity plus amiloride $\left(10^{-4} \mathrm{M}\right)$ on bioelectric parameters and $a_{\mathrm{c}}^{\mathrm{Na}}$. Asterisks depict significant $(P<0.05)$ changes induced by amiloride from baseline (KBR); + depicts significant $(P<0.05)$ change from KBR induced by luminal hypertonicity; $\ddagger$ depicts significant change from 10 -min time point with $150 \mathrm{mM}$ mannitol. Each point reflects mean $\pm \mathrm{SEM}, n=7$. Note changes in time scale. See Fig. 1 for units.

and it returned to control levels when isotonic conditions were restored (Fig. 7).

\section{Discussion}

The major finding of these studies is the evidence for the asymmetric response of human airway epithelia to changes in bathing solution osmolality. We note that these findings differ from observations with techniques using tissue fixation in canine trachea that cell shrinkage could only be induced by basal hypertonicity (22). In this study with living cells, independent techniques (Tables I and III) indicate that human nasal epithelia shrink in response to raised luminal but not serosal solution osmolality. Thus, under resting conditions, the apical membrane of human nasal airway cells is more permeable to water than the basolateral membrane. This finding is unique among epithelia from humans and other species. In other epithelia, either both cell membranes have high osmotic permeabilities, as in gallbladder (23), or, as in distal collecting duct, the apical membrane has a low osmotic permeability under resting conditions but becomes very permeable under the influence of antidiuretic hormone (24). The rate of change in epithelial thickness in cultures of airway epithelial cells was too rapid with luminal hyperosmolality (Fig 7) to assign an absolute osmotic perme- 
Table I. Input Data for Calculation by Equivalent Circuit Analysis Cell and Shunt Responses of Human Airway Epithelia to Sequence of Amiloride, Luminal Hypertonicity, and Amiloride during Hypertonicity

\begin{tabular}{|c|c|c|c|c|c|c|c|c|}
\hline Condition & $\mathrm{V}_{\mathrm{i}}{ }^{*}$ & $\mathrm{~V}_{\mathrm{a}}{ }^{\prime}$ & $V_{b}{ }^{*}$ & $\mathrm{R}_{\mathrm{t}}^{*}$ & $\mathrm{fR}_{\mathbf{a}}^{*}$ & $a_{c}{ }^{C_{*} *}$ & $a_{c}{ }^{\mathrm{Na} *}$ & $\mathrm{I}_{\mathrm{eq}}$ \\
\hline & & $m V$ & & $\mathrm{ohm} \cdot \mathrm{cm}$ & & & $m M$ & \\
\hline KBR & $-10.1 \pm 3.4$ & $-21.2 \pm 2.1$ & -31.3 & $334 \pm 70$ & $0.49 \pm 0.07$ & $36.3 \pm 3.7$ & $26.9 \pm 4.1$ & $-32.2 \pm 10.2$ \\
\hline $\mathrm{KBR}+$ amiloride & $-2.0 \pm 0.8$ & $-31.0 \pm 1.2$ & -33.0 & $387 \pm 84$ & $0.51 \pm 0.08$ & $36.7 \pm 2.0$ & $26.4 \pm 3.8$ & $-5.6 \pm 2.0$ \\
\hline Mannitol (150 mosM/liter) & $-13.3 \pm 2.6$ & $-12.0 \pm 2.7$ & -25.3 & $530 \pm 114$ & $0.47 \pm 0.07$ & $65.9 \pm 10.8$ & $34.3 \pm 6.3$ & $-27.7 \pm 7.7$ \\
\hline Mannitol + amiloride & $-2.2 \pm 0.8$ & $-24.9 \pm 2.5$ & -27.1 & $674 \pm 168$ & $0.55 \pm 0.11$ & $45.8 \pm 4.2$ & $33.3 \pm 7.1$ & $-3.9 \pm 1.7$ \\
\hline
\end{tabular}

${ }^{*}$ Mean \pm SEM; $n=7 . \quad{ }^{\ddagger}$ Derived parameter: $V_{\mathrm{b}}=V_{\mathrm{t}}+V_{\mathrm{a}}$.

ability to the apical cell membrane. Thus, until the time resolution of the measurement can be increased appropriately, we can state only that the apical membrane is the more permeable. Although the basolateral membrane osmotic permeability is low relative to that of the apical membrane, it is unlikely to be low in absolute terms, since the epithelium is thought to transport fluid (25). The asymmetric responses in cell volume induced by changes in osmolality were accompanied by specific responses in bioelectric parameters and in cellular ion activities.

Several technical considerations can be used to argue that the asymmetry in the responses to raised osmolality reflect the unique properties of human airway epithelia and do not result from differences in mixing or unstirred layers in the serosal compartment. Because the volumes and superfusion rates of the two compartments in the chamber used for electrophysiology were similar, the mixing times in the luminal and basolateral surfaces were nominally equal. Whereas the substrata to which the basolateral surface of the epithelial cells are attached may constitute a finite layer to solute permeation, this barrier would appear small based on previous studies. For example, the effects of increases in solution $\mathrm{K}^{+}$ concentrations (26) or reductions in solution $\mathrm{Cl}^{-}$concentrations (12) were sensed within $10 \mathrm{~s}$ of solution shifts. Similarly, studies of drug addition also have documented drug access to the basolateral barrier within the same time frame (13). Finally, the Cyclopore substrata used for the epithelial thickness experiments had measured hydraulic conductivities several orders of magnitude higher than epithelial cell membranes (see Methods). Thus, it is unlikely that unstirred layer or mixing artifacts can account for our findings.

The degree of the hyperosmotic challenge employed in these in vitro studies $(+150$ mosM) was selected to pertain to in vivo physiological conditions. For example, in studies of anesthe- tized dogs where airway surface liquid osmolality was directly measured, exposure to poorly conditioned air raised airway surface liquid osmolalities to a range between 430 and 480 mosM $(6,7)$. Thus, the concentration selected for most of these studies reported here (430 mosM) has been observed in vivo. In addition, the response to increased osmolalities were monotonic to increasing hypertonicity (Fig. 1), indicating that these findings are relevant to a range of in vivo conditions. Finally, it does not appear that the stimulus used was deleterious, as complete recovery occurred within a short time frame.

The rate of active ion transport as indexed by $I_{\text {eq }}$ diminishes in response to luminal hypertonicity. Previous isotope flux studies (13) and the sensitivity of the $I_{\text {eq }}$ to the $\mathrm{Na}^{+}$channel blocker, amiloride (Fig. 6), indicates that the basal $I_{\mathrm{eq}}$ in normal human nasal epithelia is a $\mathrm{Na}^{+}$absorptive current. The sensitivity of $I_{\mathrm{eq}}$ to amiloride during luminal mannitol exposure indicates that $\mathrm{Na}^{+}$transport persists during hypertonicity; thus, the decrease in $I_{\mathrm{eq}}$ induced by luminal hypertonicity probably indicates that the rate of $\mathrm{Na}^{+}$transport is reduced. There is no evidence to suggest that $\mathrm{Cl}^{-}$secretory activity is increased in response to raised luminal osmolality. Indeed, the amiloride insensitive current, an index of $\mathrm{Cl}^{-}$secretory capacity, appears to be reduced by luminal osmolality (Figs. 5 and 6 ).

The decrease in the rate of $\mathrm{Na}^{+}$absorption induced by raised luminal osmolality would appear to be due to several factors. The major factor is a decrease in the electrochemical driving force for $\mathrm{Na}^{+}$entry caused both by a depolarization of the apical membrane and by an increase in $a_{\mathrm{c}} \mathrm{Na}$. The combination of a decrease in $I_{\text {eq }}$ with an increased $a_{\mathrm{c}} \mathrm{Na}$ indicates that $\mathrm{Na}^{+}-\mathrm{K}^{+}$ -ATPase activity is also reduced by raised luminal osmolality. As shown in Table II, the calculated apical membrane $\mathrm{Na}^{+}$ permeability $\left(P_{\mathrm{a}}^{\mathrm{Na}}\right)$ is regulated in the downward direction only slightly, indicating that this regulation is a minor contributor to

Table II. Parameters Derived from Equivalent Circuit Analysis for Human Airway Epithelia in Basal, Amiloride, Luminal Hypertonic, and Hypertonicity Plus Amiloride Conditions

\begin{tabular}{|c|c|c|c|c|c|c|c|c|c|}
\hline & ${ }^{*} D F_{a}^{c l}$ & $D F_{a}^{N a}$ & $R_{\mathrm{s}}$ & $R_{\mathrm{a}}$ & $R_{\mathrm{b}}$ & $E_{\mathrm{a}}$ & $E_{\mathrm{b}}$ & $P a^{\mathrm{Cl}}$ & $P a^{\mathrm{Na}}$ \\
\hline & \multicolumn{2}{|c|}{$m V$} & \multicolumn{3}{|c|}{$\mathrm{Ohm} \cdot \mathrm{cm}^{2}$} & \multicolumn{2}{|c|}{$m V$} & \multicolumn{2}{|c|}{$\times 10^{-6} \mathrm{~cm} \cdot \mathrm{s}^{-1}$} \\
\hline \multicolumn{10}{|l|}{ Condition } \\
\hline KBR & 2.7 & -61.5 & 403 & 952 & 990 & 2.5 & -56.0 & 3.1 & 2.0 \\
\hline $\mathrm{KBR}+$ amiloride & -7.4 & - & 439 & 1,653 & 1,588 & 23.6 & -40.1 & 3.1 & - \\
\hline Mannitol (150 mosM/liter) & -4.0 & -38.0 & 692 & 1,066 & 1,202 & 8.4 & -48.3 & 1.8 & 1.8 \\
\hline Mannitol + amiloride & -7.2 & - & 790 & 2,533 & 2,073 & -17.8 & -33.1 & 1.8 & - \\
\hline
\end{tabular}

* $D F_{a}{ }^{C l}$ and $D F_{a}{ }^{\mathrm{Na}}$ denote the driving forces for $\mathrm{Cl}^{-}$and $\mathrm{Na}^{+}$across the apical membrane. 


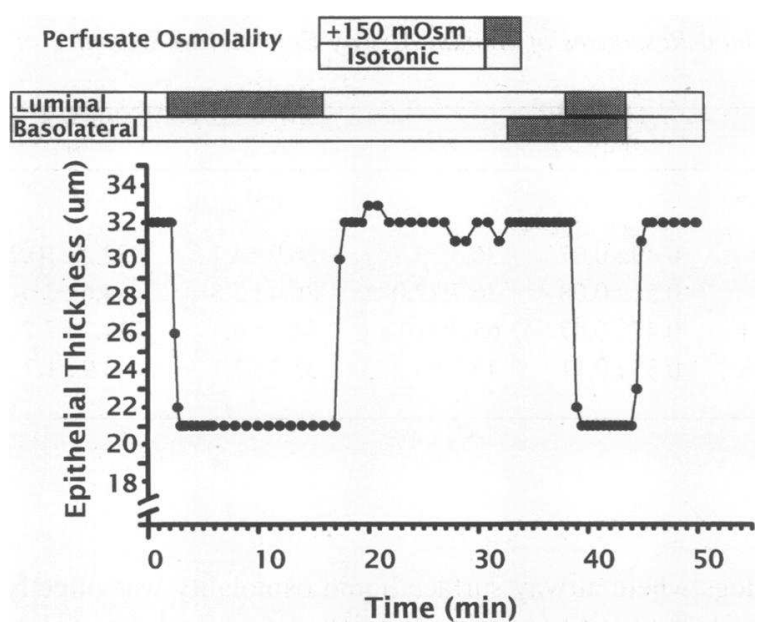

Figure 7. Effects of luminal or basolateral hypertonicity on the thickness of a cultured human airway epithelium. The epithelium was optically sectioned at $1-\mu \mathrm{m}$ intervals at each time point, and the thickness was determined from video tape records as the displacement necessary to focus from the apical membrane, marked by $1-\mu \mathrm{m}$ beads, to the surface of the substratum. The osmolality of the luminal and basolateral bathing solutions was increased as indicated by the addition of mannitol (150 $\mathrm{mM})$.

the decrease observed in $I_{\text {eq }}$ and that the major effect may be on the $\mathrm{Na}^{+}-\mathrm{K}^{+}-$ATPase.

The major intracellular response induced by luminal hypertonicity is depolarization of both the apical and basolateral membrane potentials. With regard to the apical membrane, its electromotive force, $E_{\mathrm{a}}$, became slightly more positive. Because of the increases in $a_{\mathrm{c}}{ }^{\mathrm{cl}}$ and $a_{\mathrm{c}}^{\mathrm{Na}}$, the respective equilibrium potentials, $E_{\mathrm{Cl}}$ and $E_{\mathrm{Na}}$, change: $E_{\mathrm{Cl}}$ shifts to a value closer to zero from $\sim-20 \mathrm{mV} ; E_{\mathrm{Na}}$ shifts closer to zero from a value of $\sim+40 \mathrm{mV}$. The observation that $E_{\mathrm{a}}$ shifts in the positive direction reflects in part the fact that $P_{\mathrm{a}}^{\mathrm{Cl}}$ decreases substantially, whereas $P_{\mathrm{a}}^{\mathrm{Na}}$ decreases little, thus shifting the relative contributions of $E_{\mathrm{Cl}}$ and $E_{\mathrm{Na}}$ to $E_{\mathrm{a}}$.

The decreases in the apical membrane ionic permeabilities and an expected increase in $a_{\mathrm{c}}{ }^{\mathrm{K}}$ in response to cell shrinkage should cause the cell potential to shift closer to the $\mathrm{K}^{+}$equilibrium potential and thereby hyperpolarize the cell. The observation that the cell instead depolarized, including a major depolarization of the basolateral membrane $\left(V_{\mathrm{b}}\right)$, indicates that the basolateral $\mathrm{K}^{+}$conductance is deactivated in response to luminal hypertonicity and that this may be the dominant cellular response. This notion is supported by the fact that $f R_{\mathrm{a}}$ decreases significantly during luminal hypertonicity, i.e., the fractional resistance of the basolateral membrane $\left(f R_{\mathrm{b}}\right)$ increased. In fact,

Table III. Summary of Effects of Hypertonic (+150 mM Mannitol) Solutions on the Thickness of Cultured Human Epithelia

$\begin{array}{lc}\text { Initial thickness (in TBR) }(\mu \mathrm{m}) & 25.6 \pm 3.8 \\ \text { Percent change in thickness }(+150 \mathrm{mM} \text { mannitol) } & \\ \text { Luminal hypertonicity }(n=5)(\%) & -32.0 \pm 5.2 \\ \text { Basolateral hypertonicity }(n=4)(\%) & -0.9 \pm 0.7 \\ \text { Change predicted for ideal osmometer }(\%) & -34.9\end{array}$

$R_{\mathrm{b}}$ was calculated in the model analysis to increase by $\sim 20 \%$ in response to luminal hypertonicity.

The mechanisms that regulate cellular responses to hypertonicity are not known in airway epithelia. The deactivation of the basolateral $\mathrm{K}^{+}$conductance could reflect a coupling between this conductance and $\mathrm{Na}^{+}-\mathrm{K}^{+}-\mathrm{ATPase}$ activity. Because changes in cellular $\mathrm{pH}$ have been observed during cell shrinkage in other cell types (27) and $\mathrm{pH}$ may regulate both $\mathrm{K}^{+}$conductance pathways and $\mathrm{Na}^{+}-\mathrm{K}^{+}-\mathrm{ATPase}$ activities, this parameter may play an important role in coordinating the cellular response to shrinkage. Other mechanisms could include effects of osmolality on membrane-cytoskeletal interactions, effects on cellular metabolism, and/or effects on cell $\mathrm{Ca}^{2+}$ levels.

In previous studies, amiloride had no effect on $a_{\mathrm{c}}{ }^{\mathrm{Cl}}$. In the presence of mannitol in solutions bathing the lumen, amiloride decreased $a_{\mathrm{c}}{ }^{\mathrm{Cl}}$ significantly and hyperpolarized the apical and basolateral membranes. Taken together, these data suggest that $\mathrm{Cl}^{-}$left the cell via electrically conductive pathways. As we do not know whether changes in cell volume were induced by this maneuver, we do not know whether the stability of $a_{c}{ }^{\mathrm{Na}}$ in response to amiloride reflects loss of $\mathrm{K}^{+}$or $\mathrm{Na}^{+}$with $\mathrm{Cl}^{-}$or whether $\mathrm{Cl}^{-}$was exchanged for another anion.

A recent patch clamp study on dissociated human airway cells described a whole-cell cation current that was increased in magnitude by osmotic shrinkage and decreased by swelling (28). Our study, on the other hand, indicates that both cell membrane resistances are increased by hyperosmotic exposure (Table II), a direction that is opposite to that expected for a shrinkage-activated current. It is difficult, at present, to reconcile these findings because of the different experimental models used. Our study used polarized epithelia and intracellular recordings with conventional microelectrodes, whereas the study of Chan and Nelson (28) used nonpolarized cells, whole-cell recording, and $\mathrm{K}^{+}$-free intra- and extracellular solutions to isolate the current. Thus, the shrinkage-activated, nonselective cation channel cannot be put into physiological perspective until the relevant experiments are conducted on polarized cells.

An unusual feature of the airway epithelial response to luminal hypertonicity was the behavior of the paracellular path. In most other epithelia $(29,30)$, luminal hypertonicity has been associated with a decreased resistance of the paracellular path. Two lines of evidence indicate that the resistance of the paracellular path of airway epithelia instead increases in response to cell shrinkage. First, $\boldsymbol{R}_{\mathrm{t}}$ approximately doubles in response to increased luminal osmolality. Table II shows that this increase in $R_{\mathrm{t}}$ is due to substantial increases in both the shunt $\left(R_{\mathrm{s}}\right)$ and cellular $\left(R_{\mathrm{a}}+R_{\mathrm{b}}\right)$ resistances. It is likely that the shunt pathway in the human nasal epithelial preparation $\left(\boldsymbol{R}_{\mathrm{s}}\right)$ is the paracellular path. Second, to test directly whether an increase in resistance to solute flow through the paracellular path occurred in response to luminal hypertonicity, we measured its permeability with an independent method. The observation that the permeability of radiolabeled mannitol, a marker used extensively to estimate permeability of the paracellular path in airway epithelia, was reduced by $50 \%$ (from 1.03 to $0.54 \times 10^{-7} \mathrm{~cm} \cdot \mathrm{s}^{-1}$ ) in response to luminal hypertonicity provides direct evidence that the overall permeability of the paracellular path was decreased. The mechanism of decreased permeability in an epithelium that is shrinking may be the collapse of the lateral intercellular spaces as the thickness of the epithelium decreases (Table III). This collapse may relate directly to our observations made optically that the cells lose volume solely through a decrease in height (Fig. 7). 
The measured responses of airway epithelia to luminal hypertonicity yield insights into the mechanism(s) by which airway epithelia respond to this type of challenge. First, it appears from the microelectrode and transepithelial bioelectric data that the airway epithelium does not compensate for raised luminal hypertonicity by inducing fluid secretion through activation of an active $\mathrm{Cl}^{-}$secretory current. The observed decrease in the rate of $\mathrm{Na}^{+}$absorption probably reflects only a modest compensation in the active ion transport path for the smaller water volume in ASL. However, an epithelium with a luminal membrane that is water permeable permits an acute passive compensation to occur when water moves from the cell across the apical membrane to the hypertonic luminal compartment, thereby "buffering" shifts in luminal osmolality. The fact that the relative heights of these two compartments, i.e., the cell and ASL layer, are relatively similar in vivo $(\sim 25 \mu \mathrm{m}[1,2])$ may suggest that this shift in water from the cellular to the luminal compartment is of physiological importance.

Perhaps more important, however, the fact that the luminal membrane is more water permeable than the basolateral membrane may allow the nasal airways epithelium to be configured as an osmometer to sense changes in luminal airway surface liquid osmolality and potentially effect longer-term, definitive organ-level compensations. Namely, as the ASL becomes hyperosmotic the epithelium will shrink proportionately. Thus, changes in airway surface liquids that may occur during such stimuli as rapidly breathing poorly conditioned air will be reflected in changes in epithelial cell volume. Given the fact that an osmotic driving force already exists for water flow across the airway epithelium, an appropriate response might be to increase water (blood) flow to the superficial airway wall to deliver water passively into ASL. Previous studies in animals have shown directly that mucosal blood flow in the trachea is increased in response to maneuvers that raise luminal osmolality $(31,32)$. We speculate that the vasculature responds to mediators liberated by volume-depleted epithelial cells. The nature of signals between epithelium and blood vessels may have implications for understanding the anomalous response to raised luminal toxicity that characterizes patients with reactive airways disease.

\section{Acknowledgments}

Support for these studies was received from National Heart, Lung, and Blood Institute grant HL-34322.

\section{References}

1. Hulbert, W. C. 1983. Fixation of the respiratory epithelial surface. Lab. Invest. 48:650-652.

2. Hulbert, W. C., B. B. Forster, W. Laird, C. E. Phil, and D. C. Walker. 1982. An improved method for fixation of the respiratory epithelial surface with mucous and surfactant layers. Lab. Invest. 47:354-363.

3. Welsh, M. J. 1987. Electrolyte transport by airway epithelia. Physiol. Rev. 67:1143-1184.

4. Nadel, J., B. Davis, and R. J. Phipps. 1979. Control of mucus secretion and ion transport in airways. Annu. Rev. Physiol. 41:369-381.

5. Clarke, L. L., and R. C. Boucher. 1993. Ion and water transport across airway epithelia. In Pharmacology of the Respiratory Tract: Clinical and Experi- mental. K. F. Chung and P. Barnes, editors. Marcel Dekker, New York. 505550.

6. Man, S. F. P., G. K. Adams III, and D. F. Proctor. 1979. Effects of temperature, relative humidity, and mode of breathing on canine airway secretions. J. Appl. Physiol. 46:205-210.

7. Boucher, R. C., M. J. Stutts, P. A. Bromberg, and J. T. Gatzy. 1981. Regional differences in airway surface liquid composition. J. Appl. Physiol. 50:613-620.

8. McFadden, E. R., Jr., K. A. M. Lenner, and K. P. Strohl. 1986. Postexertional airway rewarming and thermally induced asthma. New insights into pathophysiology and possible pathogenesis. J. Clin. Invest. 78:18-25.

9. McFadden, E. R., Jr., and B. M. Pichurko. 1985. Intraairway thermal profiles during exercise and hyperventilation in normal man. J. Clin. Invest. 76:10071010 .

10. Anderson, S. D., E. Daviskas, and C. M. Smith. 1989. Exercise-induced asthma: a difference in opinion regarding the stimulus. Allergy Proc. 10:215226.

11. Willumsen, N. J., and R. C. Boucher. 1989. Shunt resistance and ion permeabilities in normal and cystic fibrosis airway epithelium. Am. J. Physiol. 256:C1054-C1063.

12. Willumsen, N. J., C. W. Davis, and R. C. Boucher. 1989. Intracellular $\mathrm{Cl}^{-}$activity and cellular $\mathrm{Cl}^{-}$pathways in cultured human airway epithelium. $\mathrm{Am}$. J. Physiol. 256:C1033-C1044.

13. Willumsen, N. J., and R. C. Boucher. 1991. Sodium transport and intracellular sodium activity in cultured human nasal epithelium. Am. J. Physiol. 261:C319-C331.

14. Boucher, R. C. Human airway ion transport Am. Rev. Respir. Dis. In press. 15. Yankaskas, J. R., C. U. Cotton, M. R. Knowles, J. T. Gatzy, and R. C. Boucher. 1985. Culture of human nasal epithelial cells on collagen matrix supports. Am. Rev. Respir. Dis. 132:1281-1287.

16. Davis, C. W., and A. L. Finn. 1985. Cell volume regulation in frog urinary bladder. Fed. Proc. 44:2520-2525.

17. Boucher, R. C. 1980. Chemical modulation of airway epithelial permeability. Environ. Health Perspect. 35:3-12.

18. Spring, K. R., and A. Hope. 1979. Fluid transport and the dimensions of cells and interspaces of living Necturus gallbladder. J. Gen. Physiol. 73:287-305.

19. MacRobbie, E. A. C., and H. H. Ussing. 1961. Osmotic behavior of the epithelial cells of frog skin. Acta Physiol. Scand. 53:348-365.

20. Davis, C. W., M. L. Dowell, M. I. Lethem, and M. Van Scott. 1992. Goblet cell degranulation in isolated canine tracheal epithelium: response to exogenous ATP, ADP, and adenosine. Am. J. Physiol. 262:C1313-C1323.

21. Agard, D. A. 1984. Optical sectioning microscopy. Cellular architecture in three dimensions. Annu. Rev. Biophys. Bioeng. 13:191-219.

22. Man, S. F. P., W. Hulbert, D. S. K. Park, A. B. R. Thompson, and J. C. Hogg. 1984. Asymmetry of canine tracheal epithelium: osmotically induced changes. J. Appl. Physiol. 57:1338-1346.

23. Persson, B.-E., and K. R. Spring. 1982. Gallbladder epithelial cell hydraulic water permeability and volume regulation. J. Gen. Physiol. 79:481-505.

24. Strange, K., and K. R. Spring. 1987. Cell membrane water permeability of rabbit cortical collecting duct. J. Membr. Biol. 96:27-43.

25. Miller, S. S., J. H. Widdicombe, W. E. Finkbeiner, and P. B. McCray, Jr. 1992. Measurement of fluid transport across normal cultured airway epithelia. Pediatr. Pulmonol. Suppl. 8:278. (Abstr.)

26. Boucher, R. C., and E. H. Larsen. 1988. Comparison of ion transport by cultured secretory and absorptive canine airway epithelia. Am. J. Physiol. 254:C535-C547.

27. Grinstein, S., C. A. Clarke, and A. Rothstein. 1983. Activation of $\mathrm{Na}+/$ $\mathrm{H}+$ exchange in lymphocytes by osmotically induced volume changes and by cytoplasmic acidification. J. Gen. Physiol. 82:619-638.

28. Chan, H. C., and D. J. Nelson. 1992. Chloride-dependent cation conductance activated during cellular shrinkage. Science (Wash. DC). 257:669-671.

29. DiBona, D. R., and M. M. Civan. 1973. Pathways for movement of ions and water across toad urinary bladder. I. Anatomic site of transepithelial shunt pathways. J. Membr. Biol. 12:101-128.

30. Reuss, L., and A. L. Finn. 1975. Effects of changes in the composition of the mucosal solution on the electrical properties of the toad urinary bladder epithelium. J. Membr. Biol. 20:191-204.

31. Baile, E. M., S. Guillemi, and P. D. Pare. 1987. Tracheobronchial and upper airway blood flow in dogs during thermally induced panting. J. Appl. Physiol. 63:2240-2246.

32. Deffebach, M. E., and J. Widdicombe. 1991. The bronchial circulation In The Lung. R. G. Crystal and J. B. West, editors. Raven Press, New York. $741-757$. 